\title{
O Estado e os vencimentos da magistratura
}

Os magistrados são titulares das garantias previstas no art. 113 do Texto Constitucional Federal. Entre elas, a de irredutibilidade de vencimentos.

Perceberam, nos últimos cinco anos, vencimentos menores do que os exigidos pela irredutibilidade, porque os percentuais de 'aumento' estiveram aquém dos índices oficiais de correção do poder aquisitivo da moeda, que foram flagrantemente mais elevados, no mesmo período.

Essa diferença desfavorável caracteriza 'dano' (conforme Michel Temer) de que são vítimas os magistrados, pelo qual é responsável a Fazenda. O vulto do dano está na própria medida da diferença.

Efetivamente, os magistrados têm direito a perceber, mês a mês, vencimentos integrais, substancialmente irredutíveis (art. 113 , § II, C.F.). O Estado tem-se omitido no providenciar medidas assecuratórias de mecanismo que dê eficácia a esse direito. Essa omissão é a causa direta do 'dano', o que se vê, à evidência, pela aplicação dos critérios pertinentes propostos por Celso Antônio Bandeira de Mello.

Para que a disposição constitucional do art. 113, § III, não seja uma dição vazia e meramente retórica, significa que não se pode reduzir esses vencimentos quer direta, quer indiretamente, nem por ação, nem por omissão, como o disse, de modo categórico a Suprema Corte dos Estados Unidos, em memorável decisão de setembro de 1980, por nós comendada (In O Estado de São Paulo, $31 / 01 / 81$ ). E se há um processo indireto de esvaziamento de sua substância, processo esse detectável, nítido, palpável e notório, o resultado final, constitucionalmente vedado, é o mesmo: redução efetiva. Ora, isso é que contrasta flagrantemente com o desígnio constitucional. Isso é que frustra a eficácia da prescrição da carta magna. 
E como se trata de resultado que pode ser evitado por medidas estatais, efeito que pode ser facilmente neutralizado, é dever do Estado dar as medidas tendentes a assegurar plena eficácia à prescrição constitucional, mediante providências legislativas a cargo do Executivo (iniciativa) e Legislativo (aprovação), dado que o legislador é, na maioria dos casos, o primeiro operador da constituição, na magistral colocação de Biscaretti di Ruffia (Corso di diritto costituzionale, 9. ed. CEDAM, p. 312).

\section{Ratio luris do instituto.}

A irredutibilidade não é postulado aleatório e sem maior expressão, no contexto do nosso sistema. Ė norma básica que visa a assegurar a independência do Judiciário. Visa a garantir condições objetivas de imparcialidade da magistratura, requisito sine qua non do estado de direito, tal como postulado por Balladore IPallieri, no seu clássico Diritto Costituzionale.

Hamilton no Federalist papers, explicou aquilo - já decorrente do L'Esprit des lois de Montesquieu - que foi tão bem disciplinado no texto da constituição americana. Dissertando sobre as condições de independência do Judiciário, teve oportunidade de cunhar a significativa frase: "O poder sobre a subsistência do indivíduo equivale a poder sobre a vontade" (Sobre a Constituição dos Estados Unidos, S. Paulo IBRASA, 1964, p. 148). E, logo a seguir, sublinha: "e não se pode esperar ver jamais realizada, na prática, a completa separação do Poder Judiciário, em relação ao Poder Legislativo, em qualquer sistema que deixa o primeiro na dependência, tanto de recursos pecuniários, como das concessões acidentais do último". Os chamados predicamentos da magistratura não se configuram, assim, como meros direitos dos magistrados, mas como prerrogativas dos jurisdicionados, que têm direito a verem seus juizes protegidos objetivamente contra as ações e omissões dos demais poderes. Nisso, é semelhante à imunidade dos parlamentares, que devem exercer sua atividade político-representativa com desembaraço, independência e cercados de condições objetivas de liberdade, para exercício de seu múnus. As imunidades parlamentares também não são meros direitos dos titulares de mandato político: têm a ampla dimensão de prerrogativas dos cidadãos, que têm o direito de verem seus representantes objetivamente cercados de garantias que assegurem todo desassombro no desempenho das funções de legislar, fiscalizar, controlar, criticar, denunciar e expressar os anseios e frustrações populares (Victor Nunes Leal, Pau-
lo Brossard).

Idênticas condições objetivas de independência querem as instituições assegurar ao presidente da república, para que promova a defesa do interesse nacional com a mais ampla independência, razão pela qual só pode ser constrangido nos casos extremos de que cuida o art. 82 da constituição e na forma do art. 83.

Por tudo isso foi que o chief justice brasileiro, ínclito ministro Xavier de Albuquerque asseverou" - como as concebo, as garantias dos magistrados são uma conquista do Estado, não dos juízes" (voto no rec. h.c. 51.778-SP). Por isso, também, esse modelar juíz - no período excepcional que atravessamos, durante a vigência 
dos atos institucionais - propugnou pelo seu restabelecimento, "em toda sua plenitude, porque isso restituiria ao Estado brasileiro o timbre de aperfeiçoamento que Ihe deve ser, enquanto Estado, consubstancial" (idem).

Daí o ter o sumo jurista brasileiro, Rui Barbosa, pronunciado - na tribuna do Supremo - esta peroração:

"Porque, se este tribunal perder a sua independência, não poderar ser digno da sua missão; ele não a poderá desempenhar com utilidade e eficácia; porque, se este tribunal perder a sua independência, terá ipso facto, perdido o seu caráter de alta magistratura, não poderá afrontar as dificuldades de sua melindrosa missão. É um tribunal esse que tem muitas vezes de arrastar com o Poder Executivo e que se tem achado em divergência com o Congresso" (Comentários à constituição, coligidos por Homero Pires, 1933, v. IV, p. 62).

A irredutibilidade de vencimentos dos magistrados, nascida do especial gênio político dos 'pais da pátria', nos Estados Unidos, é um dos conspícuos meios de asseguração do princípio da independência e harmonia dos poderes, no que toca ao Judiciário (Celso Bastos, Carlos Mário Velloso).

Por isso foi trazido para o nosso direito constitucional (1891), por proposta de Rui Barbosa, aqui persistindo até a data de hoje.

Seu preciso alcance não pode ser encarado simplesmente como significando que não haverá diminuição dos vencimentos, por obra da lei. Para que corresponda à função que lhe cabe no contexto do nosso sistema - como instrumento de eficácia do magno princípio colocado no art. 6. da constituição - deve necessariamente significar também que a expressão numérica, em que se traduzem os vencimentos, há de ser corrigida, para que sua representação substancial (poder aquisitivo de fato) não se diminua.

Essa afirmação não é senão eco de sábias ponderações que, há dois séculos, a propósito da constituição norte-americana, já fazia o genial Hamilton, que escreveu no clássico Federalist papers,

"compreende-se para logo que as flutuações no valor do dinheiro e no estado da sociedade tornem inadmissivel uma taxa fixa de compensação estabelecida na constituição. O que parecesse extravagante hoje, em meio século, tornar-se-ia mesquinho e impróprio. Era, portanto, necessário deixar ao arbítrio do Legislativo variar os emolumentos de acordo com as variações das circunstâncias, sob restrições tais, contudo, que ficasse fora do alcance daquele poder alterar as condições para pior. Podem alterar-se de tempos em tempos os salários dos funcionários judiciais, conforme o momento exija, mas sem nunca abaixar a importância que qualquer juiz começou pessoalmente a receber, quando empossado no cargo". ( $p$. 149).

Tais são o sentido, o conteúdo e o alcance do preceito do art. 113, III da Lei Fundamental.

\section{A Efetiva Redução}

É a diferença entre o valor nominal da moeda e seu real poder 
aquisitivo que termina por importar concretamente na redução mensal dos vencimentos dos magistrados. A cada mês, vem perdendo substância a sua remuneração, na mesma medida em que se desvaloriza a moeda.

Esse fato é público e notório e dispensa prova. A moeda não vale o que nominalmente nela se indica. A legislação que lhe atribui curso forçado não tem a virtude de lhe assegurar a estabilidade do seu poder liberatório. Isto não só resulta patente dos fatos econômicos que o homem comum percebe na sua vida diária, como decorre da própria farta legislação ordinária que manda corrigir dívidas, valores, títulos e a sua expressão econômica. Tal verificação leva a ver que, se, de um lado, a legislação atribui determinado valor à moeda, doutro, reconhece não ser possível mantê-lo, razão pela qual determina a indexação das obrigações expressas em dinheiro.

Absurdamente, este único direito constitucionalmente garantido, quanto à real mantença de sua expressão monetária - dado que todos os demais são objeto de simples legislação ordinária - , sempre foi postergado pelo legislador.

Porque, na verdade, só os magistrados são constitucionalmente investidos desse predicamento. Ora, se, de fato, eles têm sido tradicionalmente tratados como todos os demais agentes públicos, então a irredutibilidade não tem tido nenhuma eficácia. Não tem significado nada além de uma equiparação, por disposição legal, dos magistrados e quaisquer funcionários.

Nem se diga que nenhuma lei jamais Ihes reduziu os vencimentos, como argumento tendente a afirmar a invulneração da irredutibilidade. É que isso também jamais aconteceu relativamente a todos os demais servidores públicos. Quanto aos 'empregados', submetidos a regime trabalhista, é pacífico que não podem ter seus salários reduzidos nominalmente.

Por isso, se se alegar que tal ocorre com os magistrados, então estar-se-á proclamando que seu regime é idêntico. E, portanto, que esta garantia constitucional é inócua, vã, vazia, sem sentido. Em nada os diferencia dos demais prestadores de serviço ao Estado. Assim os tratando, o Estado Ihes nega aquilo que é específico, próprio, peculiar e privativo: a irredutibilidade.

O fato danoso ai está, de modo flagrantemente evidente: a moeda com que têm sido pagos os vencimentos dos magistrados 'vale' efeitivamente 'menos' do que parece representar sua expressão gráfica. Esta representação numérica tem sido aumentada. O poder aquisitivo 'real', entretanto, que ela deve significar, não tem sido o mesmo. Pelo contrário, corrói-se e se vê diminuído, cada
mês.

O Estado tem procurado atender a isso, tentando manter os vencimentos de seus servidores, nisso, aliás, tratando os magistrados em igualdade com os demais agentes públicos. São as chama- 
Tais 'vencimentos', entretanto, não têm correspondido efetivamente à correção monetária oficial. Daí a desvalorização dos vencimentos dos juízes, com a vulneração do princípio constitucional.

Assim, a diferença entre o que percebiam há cinco anos e o que, mensalmente, vieram recebendo ao longo desse tempo, com oscilações, tem sido constantemente incrementada (além de acumulada), tornando mais chocante o contraste entre o desígnio constitucional e a realidade dos fatos.

Nítido, pois, o prejuízo. Patente o dano. Evidente a redução real, de modo a tornar a irredutibilidade uma proposição vazia, ineficaz, insignificante. E, porque danosa, impõe-se a indenização (Seabra Fagundes, Celso Antônio Bandeira de Mello).

A prova de que não foi obedecido o princípio, é que há legislação (mais solene manifestação de vontade do Estado) corrigindo o valor nominal da moeda, para uma série de casos, que importa confissão, a mais formal que o Estado pode fazer: de que o valor nominal da moeda não corresponde à sua efetiva substância.

Por isso, têm sido propostas ações ordinárias de indenização contra a Fazenda, pedindo condenação ao pagamento das diferenças de vencimentos, mês a mês, entre o que perceberam e o que deveriam ter percebido, se as 'leis de aumento' os houvessem atualizado na medida dos índices oficiais de correção monetária, tudo contado nos cinco anos anteriores à citação. Isto, de modo a manter intacto o princípio da irredutibilidade. 
withath oh

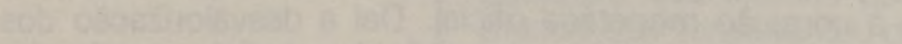

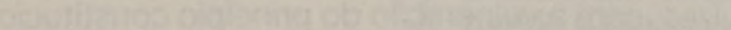

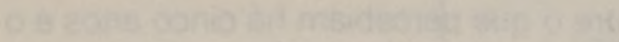

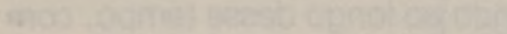

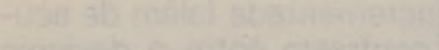

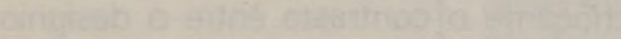

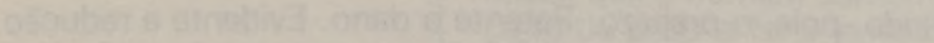

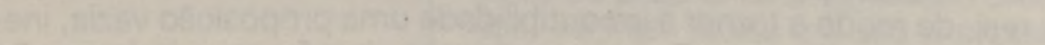
30:

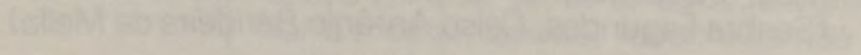

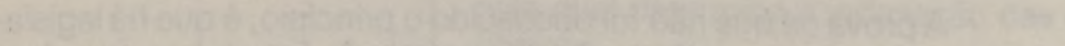

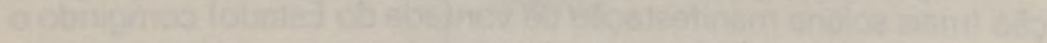

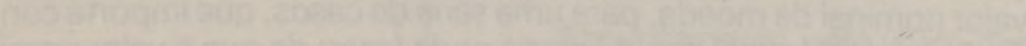
w5: and .

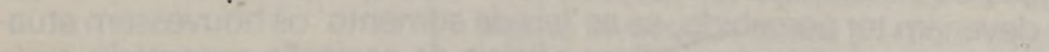

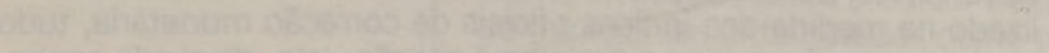

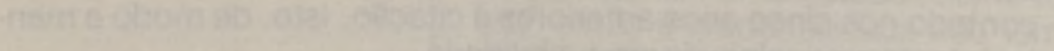

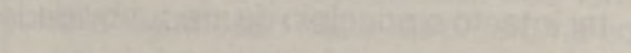

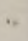

